\title{
Estudo Comparativo entre Contextos de Brincadeiras em Instituição de Acolhimento Infantil
}

\author{
Luísa Sousa Monteiro Oliveira \\ Daniela Castro dos Reis \\ Celina Maria Colino Magalhães \\ Janari da Silva Pedroso \\ Universidade Federal do Pará \\ Belém, PA, Brasil
}

\begin{abstract}
RESUMO
O objetivo deste trabalho foi descrever e comparar as brincadeiras ocorridas em contextos: estruturado (CE) e semiestruturado (CSE) em uma instituição de acolhimento infantil. Participaram 10 crianças de cinco a seis anos, com tempo de acolhimento que variou de um a 12 meses. As sessões observacionais foram realizadas no CE (brinquedoteca) e no CSE (barracão, playground e piscina). Realizaram-se 117 registros de cinco minutos, totalizando 585 minutos de observação. Os resultados mostraram que a categoria brincadeira simbólica foi a mais frequente $(43,25 \%)$, seguida da contingência física $(35,04 \%)$ e da brincadeira exploratória $(8,38 \%)$. A escolha da brincadeira variou em função do contexto. A estereotipia de gênero foi observada na escolha dos temas das brincadeiras. O estudo elucida para a oferta de contextos de brincadeira diferenciados, disponibilidade de recursos lúdicos e humanos sensíveis às inúmeras demandas das crianças, de modo que as instituições de acolhimento infantil configurem-se como contextos abrangentes de desenvolvimento.
\end{abstract}

Palavras-chave: Brincadeiras; Institucionalização; Desenvolvimento Infantil.

\begin{abstract}
Comparative Study of Contexts of Play in the Host Institution for Children

The objective of this study was to describe and compare the play contexts: structured context (SC) and semistructured context (SSC) in a host institution childish. The participants were 10 children from five to six years old, with the host time ranging from one to 12 months. The observational sessions were held in the SC (toy library) and SSC (shed, playground and pool). 117 records of five minutes were recorded, amounting to 585 minutes of observation. The results showed the symbolic play category was the most frequent $(43,25 \%)$, followed by the physical contingency $(35,04 \%)$ and the exploratory play $(8,38 \%)$. The children's choices varied depending on the context. The gender stereotyping was observed in the choice of subjects for play. The study elucidates for offering differentiated contexts of play availability of recreational resources and sensitive to the many demands of children, that the host institutions childish are configured as comprehensive development contexts.
\end{abstract}

Keywords: Play; Institutionalization; Childhood Development.

\begin{abstract}
RESUMEN
Estudio de Comparación entre Contextos de Juegos en Institución de Acogida Infantil

Este trabajo objetivó describir y comparar los juegos ocurridos en contextos: estructurado (CE) y semiestructurado (CSE) en una institución de acogida infantil. Participaron 10 niños de cinco a seis años, con tiempo de acogida que varió de uno a 12 meses. Las secciones de observación fueron realizadas en el CE (ludoteca) y el CSE (cobertizo, playground, piscina). Se realizaron 117 registros de cinco minutos, totalizando 585 minutos de observación. Los resultados mostraron la categoría juego simbólico como más frecuente $(43,25 \%)$, seguida de la contingencia física $(35,04 \%)$ y del juego exploratorio $(8,38 \%)$. La elección de los juegos cambió en función del contexto. La estereotipia de género fue observada en la elección del tema de los juegos. El estudio aclara para ofrecer contextos de juegos diferentes, disponibilidad de recursos lúdicos y humanos susceptibles a las innumerables demandas de niños, para configurar las instituciones de acogida infantil como contextos completos de desarrollo.
\end{abstract}

Palabras clave: Juegos; Institucionalización; Desarrollo Infantil. 
Estudar o desenvolvimento humano constitui-se um desafio, principalmente por se apresentar como um fenômeno complexo e multideterminado. Por esta razão, ao longo da história científica várias teorias e/ou modelos tentaram criar conceitos e construtos na busca de investigá-lo e compreendê-lo.

A história da psicologia em determinada época privilegiou olhar o desenvolvimento humano de maneira dicotomizada, ora considerando os aspectos sociais e em outras as características da pessoa. A psicologia sob um enfoque mais contemporâneo começou a estudar o desenvolvimento a partir da interação entre contexto e pessoa, sendo, portanto, o desenvolvimento humano produto e produtor dessa interação.

Entre os diversos modelos que se propõe estudar o desenvolvimento humano, apresenta-se o modelo bioecológico proposto por Bronfenbrenner (2011) que traz como alternativa entender os processos humanos, a partir da interação contexto e pessoa, sendo este contexto o ambiente onde a pessoa em desenvolvimento experiencia e se desenvolve. O modelo bioecológico traduz a natureza sistêmica e a interconexão entre pessoa-ambiente nos mais variados contextos, como um processo que leva o indivíduo a se constituir enquanto sujeito ativo do desenvolvimento humano.

A partir da perspectiva bioecológica, os níveis estrutural e funcional do indivíduo, caracterizados a partir dos aspectos biológico, psicológico e comportamental, devem ser entendidos em sua unidade e na forma como dinamicamente estão presentes nos diferentes níveis ecológicos do desenvolvimento humano. Isso significa que aspectos biopsicossociais que influenciam as relações humanas e os comportamentos podem ser percebidos e analisados a partir dos núcleos teóricos que constituem o modelo Processo - Pessoa - Contexto - Tempo (PPCT) (Bronfenbrenner, 1996/2011).

Dentre a diversidade de contextos existentes o de acolhimento institucional pode ser considerado como um espaço privilegiado para se observar o desenvolvimento, especialmente de crianças na primeira infância. Tal afirmativa é justificada pelo fato de o acolhimento institucional de crianças, ainda, configurarse como uma das principais medidas de modalidade de proteção aos infantes em situação de violação de direitos. Além disso, tal contexto é considerado como ambiente primário de desenvolvimento humano (Bronfenbrenner, 1979/1996).

$\mathrm{O}$ acolhimento institucional infantil, segundo o Estatuto da criança e do adolescente, constitui-se como uma medida provisória e excepcional, que visa assegurar a proteção da criança, utilizável como forma de transição para reintegração familiar ou, não sendo esta possível, para colocação em família substituta
(ECA - Lei 8069/1990). Preconiza-se que a criança tenha o direito ao convívio familiar, sendo a medida de acolhimento requerida em último caso, já que a família é o microssistema fundamental para o desenvolvimento adequado de crianças e adolescentes.

A criança neste novo contexto vivenciará mudanças, como rotina padronizada, convivência com pessoas: adultos e crianças desconhecidas, coletividade de roupas, espaços e recursos lúdicos, entre outros. Por outro lado, a literatura mais atual afirma que as instituições infantis constituem-se em contextos de desenvolvimento humano, tendo em vista que são espaços que devem oferecer condições reais para a vivência cotidiana e desenvolvimento de capacidades e habilidades fundamentais para a formação da personalidade e sociabilidade das crianças. Além disso, neste contexto tem-se a possibilidade da construção de novos vínculos sociais e afetivos, o estabelecimento dessas novas relações leva a criação de redes de apoio fundamentais para estas crianças que se encontram com os vínculos familiares fragilizados (Cavalcante, Silva, \& Magalhães, 2010; Siqueira \& Dell' Aglio, 2010).

A partir da compreensão do contexto de acolhimento como espaço privilegiado para estudar o desenvolvimento humano, sobretudo na primeira infância, este estudo direciona para a análise da diversidade de aspectos que conduzem a potencialidades desenvolvimentais. Entre estas podem-se citar as brincadeiras em contextos estruturados e livres como mediadoras e promovedoras do desenvolvimento de crianças na primeira infância.

A literetaura demonstra que o brincar vem sendo estudado em diversos contextos, sejam eles os rurais (Seixas, Becker, \& Bichara, 2012) e nos grandes centros urbanos, em espaços como: creches (Rosa, Kravchychyn, \& Vieira, 2010), parques públicos (Cotrim \& Bichara, 2013) e instituições de acolhimento infantil (Daunhauer, Coster, Tickle-Degnen, \& Cermak, 2010; Giacomello \& Melo, 2011).

Além dos variados contextos que a brincadeira tem sido estudada, as observações nestes ambientes têm centrado atenção especificamente em três eixos distintos: brincadeiras em contextos não-estruturados ou livres (Seixas, Becker, \& Bichara, 2012), em contextos semiestruturados (Cotrim \& Bichara, 2013) e estruturados (Rosa, Kravchychyn, \& Vieira, 2010), o que revela que independente do contexto a criança brinca.

O comportamento de brincar, materializado na brincadeira, revela o seu aspecto universal, presente no repertório de várias espécies, entre elas a humana, sendo dominante no período da infância (Bjorklund \& Pelegrinni, 2000), e específico modulado pela cultura 
onde a criança vive. Como as crianças investem tempo e energia ao brincar, e são oferecidas oportunidades para aprender enquanto elas brincam, parece haver uma necessidade que as conduzem ao brincar. Isto é verdade para os jovens mamíferos em geral, embora outros mamíferos mostrem muito menos variedade de formas de brincar do que as crianças humanas (Smith \& Pellegrini, 2008). Estes resultados sugerem que o brincar tem benefícios para o desenvolvimento que podem ser imediatos, de longa duração, ou de ambos.

Neste sentido, o brincar é um comportamento adaptativo e funcional que possui benefícios tanto para o período da infância quanto para a vida adulta. Este entendimento surge em contraposição às crenças predominantes, por muito tempo, nas ciências do comportamento e em algumas teorias do desenvolvimento, de que a função primordial da brincadeira seria a de treino de habilidades necessárias à vida adulta (Bichara \& Marques, 2011).

Além desses aspectos, de modo geral, o brincar é importante tanto para as meninas como para os meninos, pois pode servir como base para a potencialidade desenvolvimental sobre a qual as aquisições posteriores serão alicerçadas, o que trará benéficos na idade adulta. Além disso, as brincadeiras trazem como vantagens imediatas, ações adquiridas através do exercício físico, do estabelecimento e manutenção de relações sociais durante a infância (Bjorklund \& Pellegrini, 2002).

Ao mesmo tempo em que o comportamento de brincar é universal ele é moldado pela cultura, o que ocasiona uma diversidade de brincadeiras e que apresentam uma heterogeneidade de características específicas que variam em função do contexto e da cultura onde o indivíduo se desenvolve. É nessa direção que se entende que o brincar apresenta um caráter universal e ao mesmo tempo com características específicas (Bichara \& Marques, 2011).

Geary e Bjorklund (2000) afirmam que as primeiras experiências da criança relacionadas ao brincar ocorrem através da exploração do ambiente e são fundamentais para o desenvolvimento cognitivo e social. Isto ocorre por que o envolvimento inicial no brincar (diferente do brincar mais estruturado) é com frequência centrada na pessoa e focada no desenvolvimento de competências sociais, em que se aprende sobre os outros seres vivos e em como o ambiente físico é organizado. Estas habilidades referem-se a habilidades biologicamente primárias e servem como base para a aquisição posterior de competências sociais.

Além disso, ao brincar a criança estimula inúmeras competências (físicas, cognitivas, sociais e emocionais), que contribuem para o seu desenvolvimento e atuam como fator de proteção em situações estressantes
(Matsukura, Fernandes, \& Cid, 2012), uma vez que crianças em situação de risco social e pessoal podem por meio da brincadeira ressignificar suas dores, medos, sofrimentos. É nessa direção que estimular a brincadeira, pode potencializar o processo de desenvolvimento humano, por meio da reelaboração e transformação de situações conflituosas e angustiantes em experiências positivas e salutares (Marques \& Bichara, 2011; Queiroz, Maciel, \& Branco, 2006; Wanderlind, Martins, Hansen, Macarini, \& Vieira, 2006).

Portanto, a partir da compreensão da importância da brincadeira para o desenvolvimento humano, este estudo tem como objetivo descrever e comparar os tipos de brincadeiras em contextos: estruturado e semiestruturado em uma instituição de acolhimento infantil.

\section{MÉTODO}

\section{Participantes}

Participaram deste estudo 10 crianças, entre cinco e seis anos, acolhidas provisoriamente na modalidade de acolhimento institucional, sendo oito meninas e dois meninos, destes, sete crianças estavam com seis anos de idade e três estavam com cinco anos. O tempo de acolhimento dos participantes variou de um a 12 meses, distribuídos da seguinte forma: cinco crianças estavam acolhidas há um mês, uma há dois meses, duas há sete meses, uma há oito meses e uma há 12 meses. Entre os motivos de acolhimento, o abandono figurou como a principal razão (quatro casos), seguido dos maus tratos (dois casos), os demais motivos foram abuso/ violência sexual, negligência, revogação de guarda provisória e situação de risco (cada uma registrou um caso), segundo informações contidas nos prontuários. Para a escolha das 10 crianças utilizou-se os seguintes critérios: tempo de acolhimento, as crianças deveriam estar no mínimo há um mês acolhidas; ter idade entre cinco a oito anos e apresentar desenvolvimento típico. As identidades das crianças foram preservadas e para identificá-las utilizou-se a nomenclatura $\mathrm{P}$ (participante) acompanhada dos números de 1 a 10 (total de participantes), sendo identificados de P1 a P10.

\section{Contexto de pesquisa}

A pesquisa foi realizada em uma instituição localizada na região metropolitana de uma capital da região Norte do Brasil, destinada ao acolhimento provisório de crianças na faixa etária de zero a seis anos em situação de risco pessoal e social, isto é, tiveram seus direitos violados, em decorrência de negligência, 
maus tratos, violência e/ou abandono familiar. A instituição tem capacidade para atender até 50 crianças.

$\mathrm{Na}$ instituição há dois espaços que foram utilizados, nesta pesquisa, para a observação das brincadeiras das crianças: o contexto estruturado (CE) representado pela brinquedoteca, composta por seis quadrantes: Q1 - espaço de vida relacional, Q2 - espaço dos meios de transporte, Q3 - espaço dos trabalhos manuais, leitura e secretaria, Q4 - espaço do camarim, Q5 - espaço do teatro e Q6 - espaço dos brinquedos e jogos; e o contexto semiestruturado (CSE), espaço de atividade livre, representado pelos espaços barracão (galpão coberto), playground e piscina.

Neste estudo, a descrição dos três arranjos espaciais utilizadas por Meneghini e Campos-deCarvalho (2003), elaboradas por Legendre e Fontaine (1991), em estudos em creches francesas, ofereceram contribuições e parâmetros para a descrição dos contextos. Os autores denominam como arranjo aberto aquele caracterizado pela ausência de zonas circunscritas, geralmente havendo um espaço central vazio; já o arranjo visualmente aberto refere-se aquele que proporciona à criança uma visão de todo o local, sendo caracterizado pela presença de zonas circunscritas - áreas delimitadas, pelo menos em três lados, por barreiras formadas por mobiliários, parede, desnível do solo, etc.; o arranjo visualmente restrito ou arranjo fechado é aquele que possui barreiras físicas, por exemplo, um móvel alto, divide o ambiente em duas ou mais áreas, impedindo uma visão total do local pelas crianças.

Dessa forma, foram aglutinados os conceitos do arranjo aberto e arranjo visualmente aberto e denominados neste estudo de contexto semiestruturado (CSE), ou seja, aquele que possui algumas barreiras arquitetônicas, porém mais livre; e o arranjo fechado, sendo aquele que possui áreas delimitadas e barreiras físicas, denominado na presente pesquisa como contexto estruturado (CE) (Legendre \& Fontaine, 1991).

\section{Instrumento e técnica do sujeito focal}

A coleta dos dados referentes à caracterização sociodemográfica dos participantes ocorreu por meio de fontes secundárias, através da consulta às fontes documentais disponibilizadas na própria instituição (fichas individuais), e buscou identificar os itens: idade, sexo, motivo de acolhimento e tempo de acolhimento. Concomitantes aos dados secundários foram realizadas observações e gravações áudio visuais, de acordo com a técnica de sujeito-focal (Altmann, 1974), que consiste na observação direta de comportamentos espontâneos em ambiente natural, sendo a observação centrada no sujeito-focal em sessões de cinco minutos.

Para realizar a técnica, foram gravados 60 minutos de observação com cada sujeito-focal (30 minutos em cada contexto), o que totalizaria 600 minutos de observação, porém para a participante $\mathrm{P} 9$ só foi possível realizar 25 minutos de observação no $\mathrm{CE}$, o que também ocorreu com a participante P10, sendo registrados 20 minutos de observação no $\mathrm{CE}$, isto ocorreu porque as crianças recebiam visitas no horário destinado às atividades do CE. Dessa forma, obtiveram-se 117 registros de cinco minutos, totalizando 585 minutos de observação no CE e CSE.

\section{Procedimento}

A pesquisa respeitou as Normas de Pesquisa Envolvendo Seres Humanos (Res. CNS 196/96) do Conselho Nacional de Saúde, aprovada pelo Comitê de Ética e Pesquisa em Seres Humanos CEP- ICS/ UFPA com o parecer número 146/11. Para a realização da coleta de dados, foi necessária a inserção da pesquisadora no espaço como forma de minimizar o estranhamento da sua presença e da câmera de filmagem com as crianças e com os profissionais. Os primeiros contatos ocorreram três vezes por semana nos espaços utilizados para as atividades lúdicas: brinquedoteca, barracão, playground e piscina. Além do período de habituação, o objetivo desta etapa foi também o de apresentar a proposta da pesquisa às crianças e aos profissionais da instituição: técnicos e educadores/cuidadores.

A coleta de dados ocorreu no período de maio a julho de 2013, sendo que as filmagens ocorreram em dias alternados da semana, com a frequência de três visitas semanais, no turno matutino e vespertino. Buscou-se conciliar os horários de coleta a rotina da instituição, privilegiando-se dias e horários em que costumavam ocorrer mais situações de brincadeiras. A análise dos dados, por sua vez, compreendeu o período posterior a coleta até o mês de janeiro de 2014.

\section{Análise de dados}

O primeiro momento da análise se deu pela caracterização sociodemográfica dos participantes, sendo os dados analisados em planilha do Excel e apresentados por meio de estatística descritiva (dados absolutos e percentuais), considerando as variáveis: idade, sexo, motivo de acolhimento e tempo de acolhimento.

Quanto à análise dos dados referentes às observações, foi desmembrada a filmagem em um minuto, sendo descrita a frequência de vezes que a criança focal executava determinada brincadeira e 
a descrição dos tipos de brincadeira. Para a análise das observações, as sessões de cinco minutos foram transcritas na íntegra, sendo cada sessão dividida em cinco períodos de um minuto, que foram tabulados em planilha do Excel. A cada minuto foi registrado o número de vezes que a criança focal brincou de determinada brincadeira. Os dados serão apresentados em dois momentos: a frequência das brincadeiras (dados quantitativos) por meio de estatística descritiva e as descrições (dados qualitativos) por meio de categorias e seus episódios.

Para comparar as brincadeiras nos dois contextos foram utilizadas as categorias do estudo de Moraes \& Otta (2003) inspiradas nos estudos de Piaget (1971) e Parker (1984). Além destas, os autores do estudo sentiram a necessidade de incluir mais uma categoria, a brincadeira exploratória: 1) Brincadeira simbólica: consistem em tratar pessoas, objetos, animais e a si próprio atribuindo papéis diferentes dos habituais; trata-se do faz-de-conta; 2) Brincadeira exploratória: atribuiu-se esta nomenclatura aos tipos de brincadeira em que a criança manipulava algum objeto/ brinquedo, porém perdia o interesse em poucos segundos; 3) Brincadeira turbulenta: envolvem comportamentos de luta e perseguição, sendo o riso um dos principais aspectos que distinguem a brincadeira de uma luta real; 4) Contingência física: envolve exercícios físicos que põem em ação um conjunto de comportamentos (correr, pular, balançar-se, subir, descer, andar) e ainda, atividades que provocam nos objetos respostas contingentes a suas ações (atirar, pegar objetos, chacoalhar, empurrar objetos); 5) Contingência social: são brincadeiras em que há revezamento social, aparentemente motivadas e reforçadas pelo prazer associado a capacidade de produzir respostas contingentes nos outros e de responder contingentemente aos outros (esconde-esconde, fazer cócegas, imitar gestos e vocalizações); 6) Jogos de construção: são aqueles em que a criança, utilizando-se de qualquer elemento ou objeto, transforma-o em algo diferente, moldando, empilhando, enfileirando, encaixando; 7) Jogos de regras: correspondem a brincadeiras em que a regra é predominante, embora possa haver componentes sensórios-motores ou de construção.

\section{RESULTADOS E DISCUSSÃO}

As frequências de brincadeiras encontradas nos dois contextos demonstraram que há predominância da brincadeira simbólica, $(43,25 \%)$, seguida da brincadeira de contingência física $(35,04 \%)$ e da brincadeira exploratória $(8,38 \%)$, conforme Tabela 1 .
TABELA1

Frequência das brincadeiras registradas nos contextos

\begin{tabular}{|c|c|c|}
\hline $\begin{array}{l}\text { Tipos de } \\
\text { brincadeiras }\end{array}$ & $\begin{array}{c}\text { Temas e situações envolvidos } \\
\text { nas brincadeiras }\end{array}$ & $\begin{array}{l}\text { Frequência } \\
\text { por minuto \% }\end{array}$ \\
\hline Simbólica & $\begin{array}{l}\text { Casinha; mãe e filha; } \\
\text { comidinha; trabalhador; } \\
\text { escola; super-heróis; } \\
\text { princesas e bruxas; } \\
\text { cabeleireiro; médico; } \\
\text { fotógrafo; fazer compras; } \\
\text { boneco(a) assassino(a); } \\
\text { avião }\end{array}$ & 43,25 \\
\hline Exploratória & $\begin{array}{l}\text { Manipulação de objetos por } \\
\text { poucos segundos/minutos }\end{array}$ & 8,38 \\
\hline Turbulenta & Luta e perseguição & 0,68 \\
\hline $\begin{array}{l}\text { Contingência } \\
\text { Física }\end{array}$ & $\begin{array}{l}\text { Subir e descer; correr; } \\
\text { nadar; velocípede; bicicleta; } \\
\text { dançar; carregar objetos; } \\
\text { balançar; pular corda; } \\
\text { bambolê; pintar }\end{array}$ & 35,04 \\
\hline $\begin{array}{l}\text { Contingência } \\
\text { Social }\end{array}$ & Imitar gestos e vocalizações & 1,20 \\
\hline $\begin{array}{l}\text { Jogos de } \\
\text { Construção }\end{array}$ & $\begin{array}{l}\text { Quebra-cabeça; jogos de } \\
\text { encaixe }\end{array}$ & 6,84 \\
\hline $\begin{array}{l}\text { Jogos de } \\
\text { Regras }\end{array}$ & $\begin{array}{l}\text { Futebol; tacobol; jogos de } \\
\text { tabuleiro }\end{array}$ & 4,62 \\
\hline Total & 585 minutos de observação & 100 \\
\hline
\end{tabular}

Tais resultados sugerem a grande capacidade de simbolização das crianças, o que pode ajudar na ressignificação das condições adversas a que foram expostas e que levou ao acolhimento institucional. Diversos autores compartilham a premissa de que a brincadeira simbólica possibilita a criança transformar situações da realidade de acordo com seu imaginário, o que pode facilitar na reelaboração de experiências negativas em experiências de cunho positivo (Piaget, 1971; Marques \& Bichara, 2011). Para Vygotsky (1998) através do faz-de-conta as crianças querem satisfazer certos desejos que muitas vezes não podem ser satisfeitos imediatamente, como testar e experimentar os diferentes papéis existentes na sociedade (pai, mãe, filhos, trabalhador, etc.).

Resultados similares quanto à categoria de brincadeira mais frequente foram identificados nos trabalhos de Santos e Dias (2010) e de Teixeira e Alves (2008). Apesar desses estudos não terem sido realizados em contexto institucional, a brincadeira simbólica surgiu como preferida entre as crianças de um povoado rural do nordeste do Brasil e no contexto amazônico. Tais dados revelam a grande capacidade de simbolização das crianças pré-escolares. 
Além das frequências das brincadeiras nos dois contextos foi identificada uma variedade de temas e situações que caracterizam as brincadeiras (Tabela 1). Isso sinaliza que as crianças engajaram-se em categorias de brincadeiras variadas, com recursos diferenciados e ocupando os espaços existentes na instituição.

A frequência das brincadeiras distribuídas pelo gênero também foi analisada. Ressalta-se que apesar de haver uma proporção desigual entre meninas $(\mathrm{N}=8)$ e meninos $(\mathrm{N}=2)$, considera-se relevante apresentar a preferência das brincadeiras por sexo. Conforme demonstra a Tabela 2, a brincadeira simbólica foi preferida entre as meninas $(49,03 \%)$, já entre os meninos a brincadeira que obteve a maior frequência foi a de contingência física $(43,33 \%)$.

TABELA 2

Percentual dos tipos de brincadeira por sexo

\begin{tabular}{lcc}
\hline Tipos de brincadeiras & Meninas $\%$ & Meninos \% \\
\hline Simbólica & 49,03 & 20,83 \\
Exploratória & 9,68 & 3,33 \\
Turbulenta & - & 3,33 \\
Contingência Física & 32,69 & 43,33 \\
Contingência Social & 1,72 & - \\
Jogos de Construção & 3,23 & 20,83 \\
Jogos de Regras & 3,66 & 8,33 \\
Total & 100,00 & 100,00 \\
\hline
\end{tabular}

Além disso, observaram-se categorias de brincadeira em que apenas meninas engajaram-se o que também ocorreu entre os meninos, por exemplo, a brincadeira turbulenta só ocorreu entre meninos e a contingência social apenas entre meninas. Vários estudos relacionam o gênero ao tipo de brincadeira escolhida, sendo preponderante a escolha de brincadeiras simbólicas entre o gênero feminino e de brincadeiras mais vigorosas entre o gênero masculino (Santos \& Dias, 2010; Wanderlind et al., 2006).

Geary e Bjorklund (2000) argumentam que as diferenças entre gêneros que ocorrem durante as brincadeiras são facilmente observadas. Segundo os autores, os meninos tendem a envolver-se em brincadeiras mais vigorosas, que utilizam a força quando comparado às meninas, isso ocorre por que para os meninos o foco é na dominância social e na competição que servem para prepará-los para as competições fisicamente agressivas que ocorrem entre machos, que no passado serviram para aumentar o status social e a aquisição de fêmeas para os ancestrais do sexo masculino.
Em contrapartida, a brincadeira das meninas focase mais no desenvolvimento e manutenção social de relacionamentos com pessoas do mesmo gênero. Esses comportamentos servem como preparação para a vida adulta por ajudarem as meninas a aprenderem a formar e manter sistemas sociais de suporte o que gera maior estabilidade, uma habilidade que certamente foi vital para a sobrevivência e aptidão reprodutiva das mulheres ancestrais de sociedades de caçadores-coletores (Geary \& Bjorklund, 2000).

Por outro lado, a perspectiva sociocultural defende que as preferências de meninas e meninos na escolha de brincadeiras não são características meramente oriundas do corpo biológico, são construções sociais e históricas. Tal constructo permite centrar o olhar nas formas de controle do corpo infantil, um processo social e culturalmente determinado, que permite afirmar que as características tidas pela tradição como meramente masculinas e femininas resultam de esforços imbricados em uma cultura que desde o nascimento determina quais comportamentos, habilidades esperados para cada gênero (Vianna \& Finco, 2009).

Os temas das brincadeiras também costumam mudar de um gênero em relação ao outro, a pesquisa mostrou a preferência das meninas por temas relacionados à vida doméstica (cuidar da casa, preparar e servir as refeições), brincadeiras de faz-de-conta entre mãe e filha, fazer compras, entre outras. $\mathrm{Na}$ brincadeira simbólica, os meninos ou associavam-se ao grupo de meninas (quando eram aceitos) e nessas circunstâncias brincavam com o tema escolhido pelas meninas. Porém, quando a brincadeira partia deles, os temas mais comuns eram os de super-herói ou os que faziam alusão ao mundo do trabalho.

Entretanto, nem sempre apenas meninas participavam das brincadeiras simbólicas, alguns meninos integravam-se ao grupo, assumiam o papel de pai, de vilão e de outros personagens. Porém, em alguns momentos, as meninas recusavam a presença de um participante do gênero oposto e protestavam para que ele não participasse da brincadeira, apresentando o argumento de que "a brincadeira era de meninas (P6)".

Além da variável gênero, a frequência de brincadeira foi analisada por contexto. Quando os dados foram analisados a partir dos contextos, o CE e o CSE apresentaram a seguinte distribuição em termos de frequências, conforme sinalizado na Tabela 3 .

No CE verificou-se o predomínio das brincadeiras simbólicas $(64,21 \%)$ em relação às demais, sendo que as duas outras brincadeiras mais escolhidas foram: a brincadeira exploratória $(14,04 \%)$ e os jogos de construção $(14,04 \%)$. 
TABELA 3

Percentual por minuto dos tipos de brincadeiras registradas no CE e CSE

\begin{tabular}{lcc}
\hline \multicolumn{1}{c}{ Tipos de brincadeiras } & CE\% & CSE \% \\
\hline Simbólica & 64,21 & 23,33 \\
Exploratória & 14,04 & 03 \\
Turbulenta & 1,40 & - \\
Contingência Física & 3,51 & 65 \\
Contingência Social & 0,35 & 02 \\
Jogos de Construção & 14,04 & - \\
Jogos de Regras & 2,46 & 6,67 \\
Total & 100 & 100 \\
\hline
\end{tabular}

Nota. CE: contexto estruturado; CSE: contexto semiestruturado.

Entre os temas da brincadeira simbólica, o que foi mais recorrente no $\mathrm{CE}$ foi o da casinha, isso pode sugerir que mesmo em um local estranho as crianças representam a vida da família. Verificou-se que o papel materno foi enfatizado durante a brincadeira, a mãe possuía o papel de impor limites, zelar pela segurança e cuidado dos filhos, conforme pode ser observado no trecho transcrito. "Mãe, cadê a minha faca? (P4); Tu não sabes cortar (P6). P7 pega uma faca e um garfo de brinquedo e demonstra o modo como se usam os talheres. É assim olha (P7); P6 também mostra a P4 como utilizar os talheres. P4 simula que se cortou com a faca Aiiiiii! (P4); Filha eu disse pra você, eu disse, amanhã a gente vai pro médico (P6)".

No CSE emergiram os temas: comidinha, mãe e filha, trabalhador, cabeleireiro. No episódio sobre o trabalho, as crianças manipularam água e terra e referiram estar fazendo cimento. Os participantes demonstraram que já possuíam a noção de que há diferentes papéis no contexto do trabalho, como o do chefe e dos demais trabalhadores. P4 exerceu a função de liderança, tomava a iniciativa e as demais crianças obedeciam aos seus comandos, como é representado no trecho abaixo. "[...] Tu não manda, eu que mando [...] Bora todo mundo trabalhando rapidola, que nós já estamos indo pra casa (P4); É já vai dar de noite e nós ainda estamos aqui trabalhando (P8)".

Quanto às brincadeiras exploratórias, estas designavam os momentos em que as crianças manipulavam solitariamente os objetos por poucos segundos/minutos, perdendo o interesse em seguida. Pela similaridade das situações desta categoria de brincadeira em ambos os contextos, optou-se em apresentá-la apenas no CE, exemplificada no trecho: "P2 penteia os cabelos de uma boneca, logo descarta a boneca, pega uma casinha com compartimentos, manipula rapidamente o objeto e o descarta".
Os jogos de construção, por sua vez, ocorreram apenas no CE, esse resultado pode ser explicado pela diferença de oferta de recursos no CE e CSE, os recursos mais utilizados foram os jogos de encaixe de tamanhos variados. Apresenta-se um dos trechos em que esta categoria foi escolhida "A tríade P5, P8 e P7 despeja no chão as peças de um jogo de encaixe, cada um concentra-se e monta o seu objeto, P5 pede para as duas crianças olharem a torre que está construindo".

A categoria brincadeira turbulenta foi pouco evidenciada, ocorrendo apenas no CE. Apresenta-se o trecho em que a díade composta por P5 e P8 (gênero masculino), está fantasiada de super-heróis e travam uma luta "Power ranger tu vai lutar com o homem aranha (P8). P5 e P8 começam a rir. "Eu sou o Homem aranha, tu é o Power ranger (P8). (Começam a lutar, sorriem)".

Algumas hipóteses para a escolha dessas categorias de brincadeira ocorreram em função de alguns fatores, como exemplo: a organização do espaço, a oferta de recursos (brinquedos), a faixa etária e o gênero. O CE (brinquedoteca) é dividido em quadrantes com cada um vislumbrado para estimular certas competências; a alta prevalência da brincadeira simbólica pode ser explicada por alguns recursos do $\mathrm{CE}$ (brinquedos que reproduzem objetos domésticos: pratos, copos, fogão, geladeira, bonecos (as), casinha, etc.); crianças de cinco e seis anos mostram preferência pelas brincadeiras simbólicas. Sendo assim, fatores como: a oferta de recursos (brinquedos), a organização dos quadrantes, a idade das crianças (cinco e seis anos) e a prevalência de crianças do gênero feminino parecem estimular ou direcionar determinadas escolhas das crianças, colaborando para a alta frequência de brincadeira simbólica registrada no $\mathrm{CE}$.

A preferência pela brincadeira simbólica nos espaços da brinquedoteca foi demonstrada em diversos estudos (Santos \& Dias, 2010; Teixeira \& Alves, 2008). Wanderlind et al. (2006) observaram que a disponibilização de recursos parece influenciar na escolha e no tempo despendido nas brincadeiras.

Quando se analisa os dados do CSE (Tabela 3) as categorias de brincadeira que mais ocorreram foram: contingência física $(65 \%)$, seguida da brincadeira simbólica $(23,33 \%)$ e a terceira mais escolhida foram os jogos de regras $(6,67 \%)$. Dessa forma, observouse que a categoria de brincadeira que obteve maior frequência variou em função do contexto. Por exemplo, a brincadeira de contingência física obteve uma menor frequência no $\mathrm{CE}(3,50 \%)$ pelo próprio fato de este ser um espaço que limita e dificulta o desempenho de brincadeiras mais amplas (correr, pular, subir e descer, balançar, entre outras). Entretanto, no contexto em 
que isso é permitido em decorrência do arranjo dos espaços a brincadeira de contingência física obteve uma frequência maior (65\%).

O CSE apresentou uma diversidade de brincadeiras de contingência física (correr, balançar, pular, subir e descer, nadar, pintar, utilização dos brinquedos do playground). $O$ trecho apresentado exemplifica a utilização de um dos brinquedos do playground "P6 e P7 estão brincando na gangorra, as duas estão sentadas no mesmo lado, do outro lado estão P9 e o irmão de P7. P9 sai da gangorra e vai para o lado da díade de meninas, dessa forma o irmão de $\mathrm{P} 7$ fica parado no alto, pois todo o peso se concentra do outro lado".

No CE a categoria contingência física foi menos observada. Para exemplificar sua ocorrência, apresentase o episódio em que uma díade composta por meninos enche um carrinho de supermercado de brinquedo com bolas da piscina de bolinhas, a brincadeira consistia em encher o carrinho e despejar as bolas em uma das extremidades do CE, conforme o trecho "P5 e P8 tentam colocar o maior número de bolinhas possível no carrinho de supermercado, despejam as bolas no chão".

Quanto à categoria jogos de regras, no CSE, prevaleceram jogos como futebol e tacobol. No seguinte trecho uma tétrade composta por P6, P5 e P8 e educadora/cuidadora brincaram de tacobol no playground (CSE): "P6 e a educadora/cuidadora estão posicionadas em frente as garrafas, as protegem com o taco (uma raquete de ping-pong). P5 e P8 estão na outra posição segurando as bolas, esperando a oportunidade para derrubarem as garrafas". Segundo Piaget (1971), os jogos de regras têm um carácter social, com regras explícitas e criadas por um grupo, a criança tende a envolver-se com mais parceiros, em geral as competições tornam-se mais acirradas.

No CE prevaleceram as brincadeiras envolvendo jogos de tabuleiro. Apresenta-se um trecho em que a educadora/cuidadora ensina às crianças as regras de um jogo de encaçapar bolas: "A educadora/cuidadora explica a P5 e P8 as regras de um jogo em que se deve encaçapar bolas em quatro cestas, cada uma com uma pontuação diferente, em que o vencedor é aquele que fizer a maior pontuação".

Os estudos de Cotrim e Bichara (2013) e Cordazzo e Vieira (2008) também revelaram a influência do contexto para a escolha da brincadeira, sendo que os contextos mais livres estimulam a ocorrência de brincadeiras motoras. Por outro lado, contextos mais delimitados fisicamente (presença de paredes, espaço restrito) diminuem a ocorrência de tais comportamentos.

Um dos fatos que chama atenção consiste na diferença entre as categorias de brincadeira em que as crianças se engajaram nos contextos, percebeu-se que no CE houve uma diversidade maior de brincadeiras, quando comparado com o CSE. Uma possível explicação para esse fato consiste no oferecimento de brinquedos em cada contexto, o CE reunia uma grande variedade de brinquedos, o CSE, por sua vez, possuía espaço mais livre e escassez de recursos materiais (brinquedos), restringidos aos brinquedos do playground.

Percebeu-se que apesar dos recursos materiais no CSE serem limitados, as crianças parecem ter aproveitado a disponibilidade do espaço físico para o engajamento em brincadeiras mais amplas (motoras), que necessitam de espaço livre de barreiras arquitetônicas. Sendo assim, no CSE prevaleceram jogos como o futebol e o tacobol, a utilização dos brinquedos do playground, o uso de materiais como terra, água, folhas das árvores, que passaram a ter outro significado a partir das demandas das crianças, sendo utilizados em várias brincadeiras.

Os resultados dos estudos de Marques (2010), Luz e Kuhnen (2013) e Cotrim e Bichara (2013) confirmam a influência do contexto para a escolha do tipo de brincadeira, sendo preponderantes as brincadeiras de contingência física (exercícios motores) em contextos externos, com poucas barreiras arquitetônicas. Para Pellegrini e Smith (1998) as crianças pré-púberes sentem uma grande necessidade de engajamento em atividades físicas e o exercício de tais habilidades é fundamental para o desenvolvimento psicomotor. Para tal, são essenciais contextos que propiciem a ocorrência de tais comportamentos, já que espaços muito fechados e limitados, com paredes e outros arranjos dificultam a ocorrência de tais atividades.

Uma das possíveis conclusões que este estudo chegou foi a de que a oferta de contextos diferenciados, tanto os mais livres quanto os mais delimitados fisicamente (com a presença de barreiras arquitetônicas) é benéfico ao desenvolvimento, pois estimula e influencia a criança a engajar-se em um rol diversificado de brincadeiras, o que irá estimular as mais variadas competências (físicas, cognitivas, sensoriais, sociais).

\section{CONSIDERAÇÕES FINAIS}

A pesquisa revelou que independente do contexto, as crianças arranjam uma forma de brincar, o que revela a natureza universal do comportamento de brincar. Identificou-se que o contexto pode influenciar na escolha dos tipos de brincadeira.

No contexto estruturado, prevaleceram às brincadeiras simbólicas, em especial entre as meninas, 
outros estudiosos encontraram dados similares, sendo preponderante a escolha de brincadeiras simbólicas entre o gênero feminino e de brincadeiras mais vigorosas entre o gênero masculino. As temáticas das brincadeiras também foram influenciadas pelo gênero, meninas preferiram brincar com temas relacionados à vida doméstica; enquanto os meninos escolheram temas relacionados a super-heróis e ao mundo do trabalho. No contexto semiestruturado, prevaleceram às brincadeiras de contingência física em ambos os gêneros. Tais dados corroboram a literatura que afirma que as crianças tendem a envolver-se em atividades físico/motoras em espaços com poucas barreiras arquitetônicas.

As verbalizações das crianças, sobretudo, durante as brincadeiras simbólicas parecem ter feito alusão ao contexto familiar, pois as falas referiamse, em geral, a aspectos do cotidiano de uma família de ambiente urbano. Através das verbalizações verificou-se que aspectos relacionados ao cotidiano do contexto institucional estavam ausentes, sendo a referência à rotina institucional pouco evidenciada. Uma possível explicação para esse dado consiste no tempo de acolhimento das crianças, seis participantes estavam acolhidas em período inferior a três meses e nove estavam em situação de primeiro acolhimento institucional.

Assim, considera-se que este estudo constituise em mais um esforço que visa elucidar questões referentes às brincadeiras, compreendendo-as levando em consideração os contextos em que ocorrem, as características da pessoa em desenvolvimento e da relação entre estes fatores, o que possibilita um olhar mais acurado e global acerca do desenvolvimento infantil a partir dos pressupostos teóricos da bioecologia do desenvolvimento humano. Dessa forma, esta pesquisa sinaliza para a oferta de contextos diferenciados em instituições de acolhimento infantil, que devem ser compreendidas como contextos abrangentes de desenvolvimento humano nos primeiros anos de vida. Uma possível limitação deste estudo consiste na não contemplação de todos os espaços da instituição para a observação das brincadeiras, como os dormitórios, além de uma amostra reduzida. Ressaltam-se a importância de pesquisas que busquem analisar as brincadeiras nos mais variados contextos.

\section{REFERÊNCIAS}

Altmann, J. (1974). Observational study of behavior sampling methods. Behavior, 49, 227-267. http://dx.doi. org/10.1163/156853974X00534

Bjorklund, D. F. \& Pellegrini, A. D. (2000). Child Development and Evolutionary Psychology. Child Development, 71(6), 1687-1708. http://dx.doi.org/10.1111/1467-8624.00258

Bjorklund, D. F. \& Pellegrini, A. D. (2002). The origins of human nature: Evolutionary developmental psychology. Washington, D.C.: American Psychological Association. http://dx.doi.org/10.1037/10425-000

Brasil (1990). Estatuto da criança e do adolescente. Diário Oficial da União. Lei no 8069, de 13 de julho de 1990. Brasília, DF.

Bronfenbrenner, U. (1996). A ecologia do desenvolvimento humano: Experiências naturais e planejadas. Tradução de M. A. Verosese. Porto Alegre. Artes Médicas. (Trabalho original publicado em 1979).

Bronfenbrenner, U. (2011). Biologia do desenvolvimento humano: tornando os seres humanos mais humanos. Porto Alegre: Artes Médicas.

Cotrim, G. S. \& Bichara, I. D. (2013). O brincar no ambiente urbano: limites e possibilidades em ruas e parquinhos de uma metrópole. Psicologia: Reflexão e Crítica, 26(2), 388-395. http://dx.doi.org/10.1590/S0102-79722013000200019

Cordazzo, S. T. D. \& Vieira, M. L. (2008). Caracterização de brincadeiras de crianças em idade escolar. Psicologia: Reflexão e Crítica, 21(3), 365-373. http://dx.doi.org/10.1590/S0102-79722008000300004

Cavalcante, L. I. C., Silva, S. S. C. da, \& Magalhães, C. M. C. (2010). Institucionalização e reinserção familiar de crianças e adolescentes. Revista Mal Estar e Subjetividade, 10(4), 1147-1172.

Daunhauer, L. A., Coster, W. J., Tickle-Degnen, L., \& Cermak, S. A. (2010). Play and Cognition Among Young Children Reared in an Institution. Physical and Occupational Therapy in Pediatrics, 30(2), 83-97. http://dx.doi. org/10.3109/01942630903543682

Geary, D. C. \& Bjorklund, D. F. (2000). Evolutionary developmental psychology. Child Development, 71, 57-65. http:// dx.doi.org/10.1111/1467-8624.00118

Giacomello, K. J. \& Melo, L. de L. (2011). Do faz de conta à realidade: compreendendo o brincar de crianças institucionalizadas vítimas de violência por meio do brinquedo terapêutico. Ciência \& Saúde Coletiva, 16 (Suppl. 1), 1571-1580. http://dx.doi.org/10.1590/S1413-81232011000700093

Legendre, A. \& Fontaine, A. M. (1991). The effects of visual boundaries in two-year-olds' playrooms. Children's Environments Quarterly, 8, 2-16.

Psico, Porto Alegre, v. 46, n. 3, pp. 311-320, jul.-set. 2015 
Luz, G. M. da \& Kuhnen, A. (2013). O uso dos espaços urbanos pelas crianças: explorando o comportamento do brincar em praças públicas. Psicologia: Reflexão e Crítica, 26(3), 552-560. http://dx.doi.org/10.1590/S0102-79722013000300015

Marques, R. L. \& Bichara, I. D. (2011). Em cada lugar um brincar: reflexão evolucionista sobre universalidade e diversidade. Estudos de Psicologia, 28(3), 381-388. http://dx.doi.org/10.1590/S0103-166X2011000300010

Matsukura, T. S., Fernandes, A. D. S. A., \& Cid, M. F. B. (2012). Fatores de risco e proteção à saúde mental infantil: o contexto familiar. Revista Terapia Ocupacional Universidade de São Paulo, 23(2), 122-129. http://dx.doi. org/10.11606/issn.2238-6149.v23i2p122-129

Meneghini, R. \& Campos-de-Carvalho, M. (2003). Arranjo espacial na creche: espaços para interagir, brincar isoladamente, dirigir-se socialmente e observar o outro. Psicologia: Reflexão e Crítica, 16(2), 367-378. http://dx.doi. org/10.1590/S0102-79722003000200017

Moraes, M. S. \& Otta, E. (2003). Entre a serra e o mar. In A. M. A. Carvalho, C. M. C. Magalhães, F. A. R. Pontes \& I. D. Bichara (Eds.). Brincadeira e cultura: viajando pelo Brasil que brinca (pp. 127-156). São Paulo, SP: Casa do Psicólogo.

Parker, S. T. (1984). Playing for keeps: An evolutionary perspective on human games. In P. K. Smith (Ed.). Play in animals and humans (pp. 271-293). Oxford, UK: Basil Blackwell.

Smith, P. K. \& Pellegrini, A. (2008). Learning through play. In R. E. Tremblay, M. Boivin \& R. D. E. V. Peters (Eds.). Encyclopedia on Early Childhood Development [online]. Montreal, Quebec: Centre of Excellence for Early Childhood Development and Strategic Knowledge Cluster on Early Child Development.

Pellegrini, A. D. \& Smith, P. K. (1998). Physical activity play: The nature and function of a neglected aspect of play. Child Development, 69, 577-598. http://dx.doi.org/10.2307/1132187

Piaget, J. (1971). Seis estudos de Psicologia. Rio de Janeiro: Forense.

Queiroz, N. L. N., Maciel, D. A., \& Branco, A. U. (2006). Brincadeira e desenvolvimento infantil: um olhar sociocultural construtivista. Paidéia, 16(34), 169-179. http://dx.doi.org/10.1590/S0103-863X2006000200005

Rosa, F. V., Kravchychyn, H., \& Vieira, M. L. (2010). Brinquedoteca: a Valorização do Lúdico no Cotidiano Infantil da Pré-Escola. Barbarói, 33(2), 08-27.

Santos, A. K. \& Dias, A. M. (2010). Comportamentos lúdicos entre crianças do nordeste do Brasil: categorização de brincadeiras. Psicologia Teoria e Pesquisa, 26(4), 585-594. http://dx.doi.org/10.1590/S0102-37722010000400002

Seixas, A. A. C., Becker, B., \& Bichara, I. D. (2012). Reprodução interpretativa e cultura de pares nos grupos de brincadeira da Ilha dos Frades/BA. Psico [online], PUCRS, 43(4), 541-551.

Siqueira, A. C. \& Dell'Aglio, D. D. (2010). Crianças e adolescentes institucionalizados: desempenho escolar, satisfação de vida e rede de apoio social. Psicologia: Teoria e Pesquisa, 26(3), 407-415. http://dx.doi.org/10.1590/S010237722010000300003

Teixeira, S. R. S. \& Alves, J. M. (2008). O contexto das brincadeiras das crianças ribeirinhas da Ilha do Combu. Psicologia: Reflexão e Crítica, 21(3), 374-382. http://dx.doi.org/10.1590/S0102-79722008000300005

Vianna, C. \& Finco, D. (2009). Meninas e meninos na Educação Infantil: uma questão de gênero e poder. Cadernos Pagu, (33), 265-283. http://dx.doi.org/10.1590/S0104-83332009000200010

Vygotsky, L. S. (1998). A formação social da mente. São Paulo: Martins Fontes.

Wanderlind, F., Martins, G. Dal. F., Hansen, J., Macarini, S. M., \& Vieira, M. L. (2006). Diferenças de gênero no brincar de crianças pré-escolares e escolares na brinquedoteca. Paidéia (Ribeirão Preto), 16(34), 263-273. http://dx.doi. org/10.1590/S0103-863X2006000200014

\footnotetext{
Autores:

\author{
Endereço para correspondência: \\ Luísa Sousa Monteiro Oliveira \\ Universidade Federal do Pará \\ Núcleo de Teoria e Pesquisa do Comportamento \\ Av. Augusto Correa s/n - Guamá \\ CEP 66095-900 Belém, PA, Brasil
}

Luísa SOUSA MONTEIRo OLIVEIRA - Mestre, Universidade Federal do Pará DANIEla CASTRo dos ReIS - Doutorando, Universidade Federal do Pará. Celina Maria Colino Magalhães - Doutor, Universidade Federal do Pará. JANARI DA SILVA PEDROSO - Doutor, Universidade Federal do Pará.

Recebido em: 07.07.14

Aceito em: 16.03 .15 